\title{
On the fine structure of medium energy electron fluxes in the auroral zone and related effects in the ionospheric D-region
}

\author{
J. K. Hargreaves ${ }^{1,2}$, M. J. Birch ${ }^{2,3}$, and D. S. Evans ${ }^{4}$ \\ ${ }^{1}$ Department of Communication Systems, Lancaster University, UK \\ ${ }^{2}$ Jeremiah Horrocks Institute for Astrophysics and Supercomputing, University of Central Lancashire, Preston, UK \\ ${ }^{3}$ John Tyndall Institute for Nuclear Research, University of Central Lancashire, Preston, UK \\ ${ }^{4}$ Space Environment Centre, NOAA, Boulder, USA
}

Received: 19 March 2010 - Accepted: 12 April 2010 - Published: 10 May 2010

\begin{abstract}
This study is based on measurements of trapped and precipitated electrons of energy $>30 \mathrm{keV}$ and $>100 \mathrm{keV}$ observed by polar orbiting environmental satellites during overpasses of the imaging riometer at Kilpisjärvi, Finland. The satellites are in sun-synchronous orbits of about $850 \mathrm{~km}$ altitude, recording the electron fluxes at 2 -s time resolution. The riometer measures the radiowave absorption at $38.2 \mathrm{MHz}$, showing the spatial pattern within a $240 \mathrm{~km}$ field of view.

The analysis has focussed on two areas. Having found a close correlation between the radiowave absorption and the medium-energy electron fluxes during satellite overpasses, empirical relationships are derived, enabling one quantity to be predicted from the other for three sectors of local time. It is shown that small-scale variations observed during a pass are essentially spatial rather than temporal.

Other properties, such as the spectra and the relation between precipitated and trapped components, are also considered in the light of the theory of pitch angle scattering by VLF waves. It is found that the properties and behaviour depend strongly on the time of day. In the noon sector, the precipitated and trapped fluxes are highly correlated through a square law relationship.
\end{abstract}

Keywords. Magnetospheric physics (Auroral phenomena; Energetic particles, precipitating; Energetic particles, trapped)

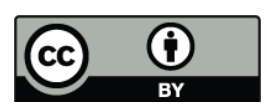

Correspondence to: J. K. Hargreaves (j.hargreaves@lancaster.ac.uk)

\section{Introduction}

Ever since auroral radio absorption was identified as a distinct phenomenon (Reid and Collins, 1959) - though they described it as predominantly a night-time occurrence and attributed it to increased collision frequency in the E-region (both erroneous!) - there has been interest in relating the absorption effects to the incoming energetic particles causing them: to identify the nature of the particles and their energy; to determine the height of the absorption which depends on the energy; to be able to predict one quantity from the other; and to learn the physics involved.

Maehlum and O'Brien (1963) and McDiarmid et al. (1963) raised statistical arguments based on the occurrence and location of auroral absorption and of energetic electron precipitation detected by the low-orbit satellites Injun I and Alouette I, to argue that the latter was likely to be the cause of the former. The first direct connection was demonstrated by Jelly et al. (1964) using measurements of $>40 \mathrm{keV}$ electrons on the early Canadian satellite Alouette I when passing over, or close to, the field of view of wide-beam riometers operating at, or near to, $30 \mathrm{MHz}$. They reported absorption exceeding $0.2 \mathrm{~dB}$ when the precipitated flux exceeded $2 \times 10^{4} \mathrm{~cm}^{-2} \mathrm{~s}^{-1} \mathrm{sr}^{-1}$ and, assuming the absorption (A) to be proportional to the square root of the flux $(J)$, they derived the relationships

$A=4 \times 10^{-3} \sqrt{J}$
$A=2 \times 10^{-3} \sqrt{J}$

for day and night respectively. The difference was attributed (wrongly, it is now thought) to photodetachment in the sunlit D-region of the ionosphere.

Unlike Alouette I, the US satellite Injun III was able to measure the precipitated and trapped components of the 
electron flux simultaneously. Parthasarathy et al. (1966) observed that the trapped flux was usually greater than the precipitated component by a factor of 10 to 100 , and the pitchangle distribution only approached isotropy when the intensity was high. Taking day and night observations together they related $30 \mathrm{MHz}$ absorption and $>40 \mathrm{keV}$ precipitated flux by

$A=3.3 \times 10^{-3} \sqrt{J}$

which agrees well with the Jelly et al. results.

Some comparisons have been made between the absorption detected with riometers and the electron fluxes at geosynchronous orbit (Baker et al., 1981; Collis et al., 1983). This configuration has the advantage of continuity at a single location and the spectral resolution may be good, but the magnetic conjugacy between the satellite and ground station may be uncertain, there is no information about the spatial distribution of the particles, and the loss cone (which is very narrow at the equator) may be smaller than the reception cone of the detector for precipitated particles.

The present study returns to comparisons with low-orbit data, concentrating on short-term variations of electron flux detected at about $850 \mathrm{~km}$ altitude, while the satellite passes through the field of view of an imaging riometer showing spatial detail within the absorption patch. We consider (i) short-term variation of the electron flux, (ii) detailed empirical relationships between the fluxes and the variation of radio absorption during overpasses of the imaging riometer, (iii) interpretation of the results in relation to the theory of pitch-angle scattering, and (iv) time of day variations, including change of spectrum.

\section{Observations and data}

The NOAA polar orbiting environmental satellites (POES) are in sun-synchronous orbits of $90 \mathrm{~min}$ period at altitude $850 \mathrm{~km}$. Their instrumentation (Evans and Greer, 2004) includes the Medium Energy Proton and Electron Detectors (MEPED) from which we shall be concerned with the fluxes of electrons in the energy bands $30-2500 \mathrm{keV}$ and 100 $2500 \mathrm{keV}$. Each satellite carries two identical solid state detector telescopes, one pointing almost vertically and the other horizontally, each having a reception cone of $30^{\circ}$ diameter. (There is actually a $9^{\circ}$ offset in each case so that the field of view is clear of spacecraft structure.)

At high latitudes the "vertical" telescope points at an angle to the geomagnetic field which depends on the satellite's latitude and longitude. For our purposes we take an average value of $17^{\circ}$. At $850 \mathrm{~km}$ this telescope collects precipitating electrons that would penetrate to the atmosphere. The "horizontal" telescope points at an average angle of $78^{\circ}$ or $102^{\circ}$ to the field, depending on the position of the spacecraft in the orbit. This observes trapped electrons which would mirror before reaching the atmosphere.
The geometric factor for converting the count rate $\left(C, \mathrm{~s}^{-1}\right)$ to flux $\left(F, \mathrm{~cm}^{-2} \mathrm{~s}^{-1} \mathrm{sr}^{-1}\right)$ is 100 . Each of the telescopes provides count rates for the energy bands stated above. We shall refer to these as the " $30 \mathrm{keV"} \mathrm{and} \mathrm{"} 100 \mathrm{keV"} \mathrm{rates} \mathrm{respec-}$ tively, it being understood that they are integral rates above the threshold.

Overpasses of POES satellites across a $240 \mathrm{~km}$ square centred on Kilpisjärvi, Finland $\left(69.05^{\circ} \mathrm{N}, 20.79^{\circ} \mathrm{E}, L=5.9\right)$ were selected for comparison with the radio-wave absorption observed with the $38.2 \mathrm{MHz}$ imaging riometer at that site (Browne et al., 1995). In each of the energy ranges the electrons are counted for one-second periods from each telescope alternately. Thus the time resolution is $2 \mathrm{~s}$ in each case. During an overpass the number of samples taken was generally 18 to 20 , giving a spatial resolution of about $12 \mathrm{~km}$ over the ground. The data used in the study are from the satellites NOAA-12 and NOAA-14 between late 1994 and early 1996, and comprise 54 selected overpasses which fall into three local time groups.

\section{Rapid variations of flux}

Samples of the precipitated and trapped count rates from the $30 \mathrm{keV}$ and $100 \mathrm{keV}$ counters are shown in Fig. 1. It is noteworthy that at the same energy the precipitated flux is almost invariably less than the trapped, but the relative variations from point to point are considerably larger. Some passes seem to show quasi-periodic variation with a period of 5 or 6 samples i.e. 10 to $12 \mathrm{~s}$ in time, or 60 to $72 \mathrm{~km}$ in distance. The patterns of variations are similar for the $30 \mathrm{keV}$ and $100 \mathrm{keV}$ particles.

The amount of variability depends on the time of day. Figure 2 gives statistics of the maximum point-to-point change of flux (as a ratio) observed during each overpass, divided into three time groups ( $\sim$ 01:00 UT, $\sim 07: 00$ UT and $\sim 11: 00$ UT) according to the satellite orbits. In local time the groups can be taken to represent night $(\sim 02: 30 \mathrm{LT})$, morning $(\sim 08: 30 \mathrm{LT})$ and noon $(\sim 12: 30 \mathrm{LT})$. These groups comprise 10,31 and 13 passes, respectively, each of which crosses the latitude of Kilpisjärvi within $5^{\circ}$ of longitude. It is clear that the trapped flux seldom varies by more than a factor of 3 between samples, and in half the cases by less than a factor of 2. On the other hand, the variability of the precipitated flux is larger and depends on the local time. In the morning group the maximum point-to-point change can exceed a factor of 100 , and in half the cases exceeds a factor of 45 at $30 \mathrm{keV}$ or 25 at $100 \mathrm{keV}$.

The statistics are summarised in more detail in Table 1. These again refer to the maximum change from point to point during each overpass, and they are divided according to time of day, energy, and whether trapped or precipitated. Median values are given (from Fig. 2), and also the percentage of points for which the maximum ratio " $\leq 2$ " (for the trapped 

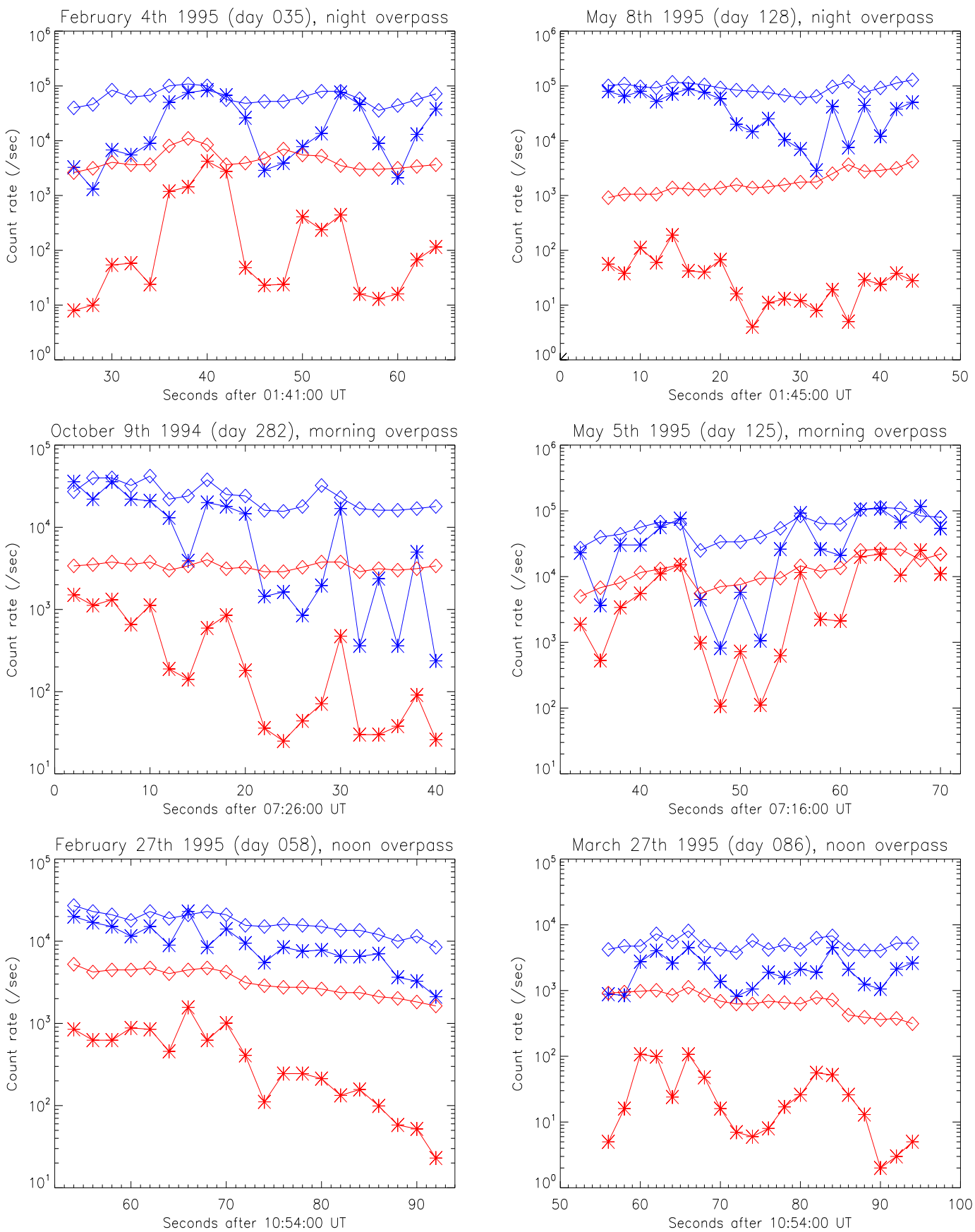

Fig. 1. Variation with time of trapped and precipitated count rates (/s) for both $30 \mathrm{keV}$ and $100 \mathrm{keV}$ detector channels, for selected passes during night, morning, and noon (blue $=30 \mathrm{keV} ;$ red $=100 \mathrm{keV}$; asterisks $=$ precipitated; diamonds $=$ trapped).

particles) and " $\leq 10,>10$ to $\leq 100$ or $>100$ " (for the precipitated particles). The following conclusions are noted:

1. In the case of the trapped fluxes, the maximum pointto-point change during an overpass is generally small, the median being less than a factor of 2 . Values greater than 3 are rare. The values are somewhat smaller in the morning group than those at night or at noon.
2. The maximum point-to-point changes in the morning group are generally much greater in the precipitated flux than in the trapped, $60-70 \%$ of values being between factors 10 and 100. The factor 100 was exceeded in $16 \%$ of the overpasses. The results are similar for 30 and $100 \mathrm{keV}$. 

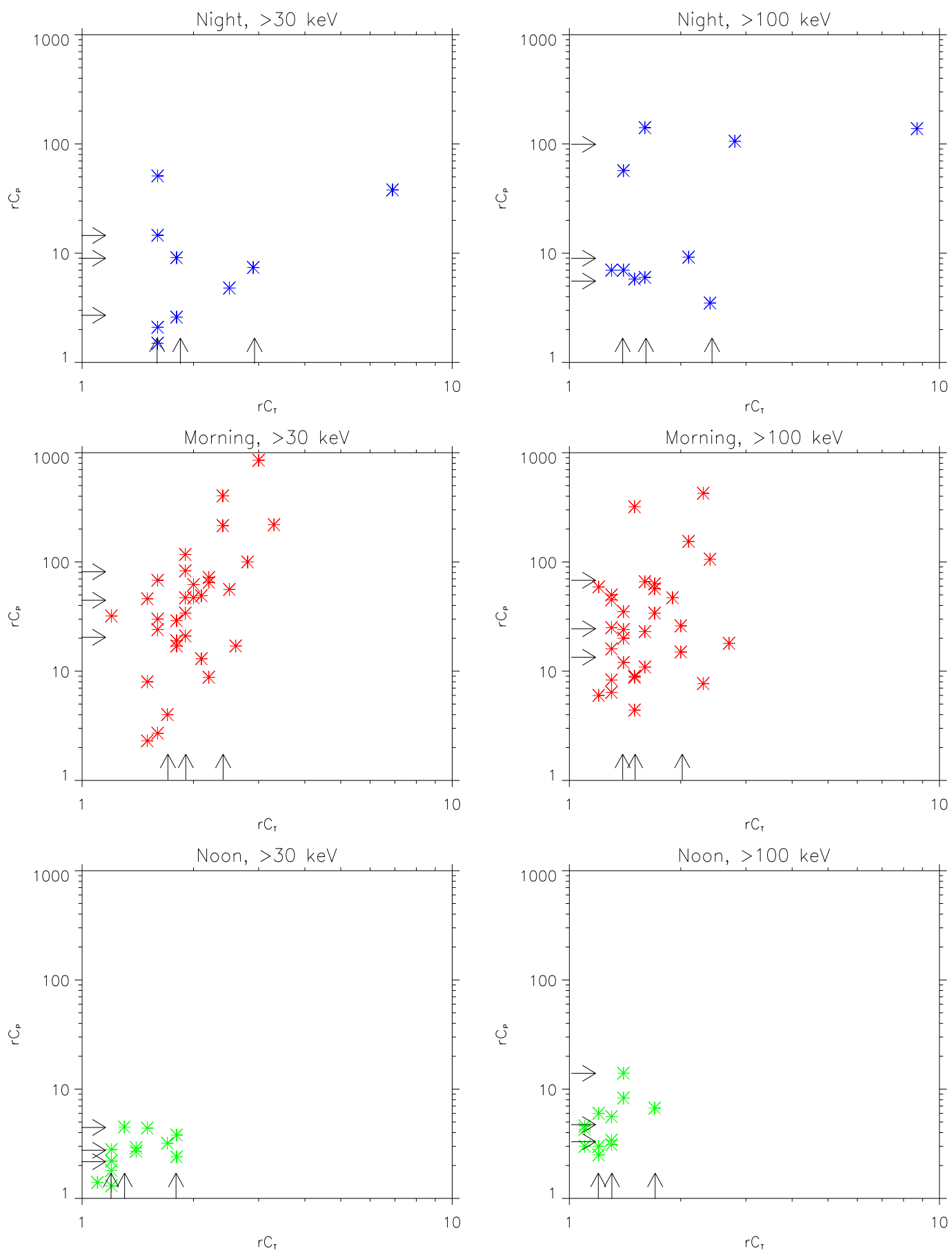

Fig. 2. Statistics of the maximum point-to-point change of precipitated $\left(r C_{\mathrm{P}}\right)$ against trapped $\left(r C_{\mathrm{T}}\right)$ flux observed during each overpass, expressed as ratios, for "night" ( $\sim 02: 30$ LT), "morning" ( $\sim 08: 30$ LT) and "noon" ( $\sim 12: 30$ LT) sectors. (The arrows mark the medians and quartiles.)

3. The relative variation of precipitated flux is smaller at night than in the morning group, the median being about 8 , which is 3 to 4 times smaller than for the morning.

4. The changes are smaller again at noon, and the median ratios for the precipitated particles are only 2 to 3 times those for the trapped component. Virtually all noon values are below a factor of 10 , and below 5 at $30 \mathrm{keV}$. This seems to indicate a remarkable change of character in only $4 \mathrm{~h}$ of local time. 
Table 1. Summary of the statistics in Fig. 2, showing the maximum change from point to point during each overpass, divided according to time of day, energy, and whether trapped or precipitated.

\begin{tabular}{|c|c|c|c|c|c|c|c|c|c|c|c|c|c|c|c|c|}
\hline \multirow[t]{2}{*}{ LT group } & \multicolumn{3}{|c|}{$T_{30}$} & \multicolumn{3}{|c|}{$T_{100}$} & \multicolumn{5}{|c|}{$P_{30}$} & \multicolumn{5}{|c|}{$P_{100}$} \\
\hline & No. & Median & $\% \leq 2$ & No. & Median & $\% \leq 2$ & No. & Median & $\% \leq 10$ & $\begin{array}{c}10<\% \\
\leq 100\end{array}$ & $\%>100$ & No. & Median & $\% \leq 10$ & $\begin{array}{c}10<\% \\
\leq 100\end{array}$ & $\%>100$ \\
\hline Morning & 31 & 1.9 & 61 & 31 & 1.5 & 81 & 31 & 45 & 16 & 68 & 16 & 31 & 25 & 22 & 61 & 16 \\
\hline Noon & 13 & 1.3 & 100 & 13 & 1.3 & 100 & 13 & 2.7 & 100 & 0 & 0 & 12 & 4.5 & 92 & 8 & 0 \\
\hline Night & 10 & 1.8 & 60 & 10 & 1.6 & 60 & 10 & 8.2 & 60 & 40 & 0 & 10 & 8.0 & 60 & 40 & 0 \\
\hline
\end{tabular}

(a)

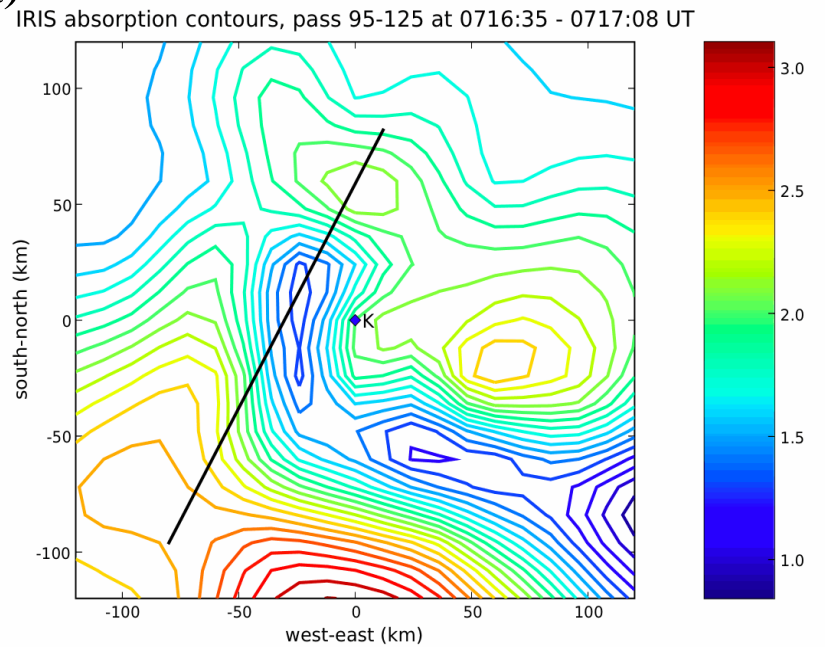

(b)

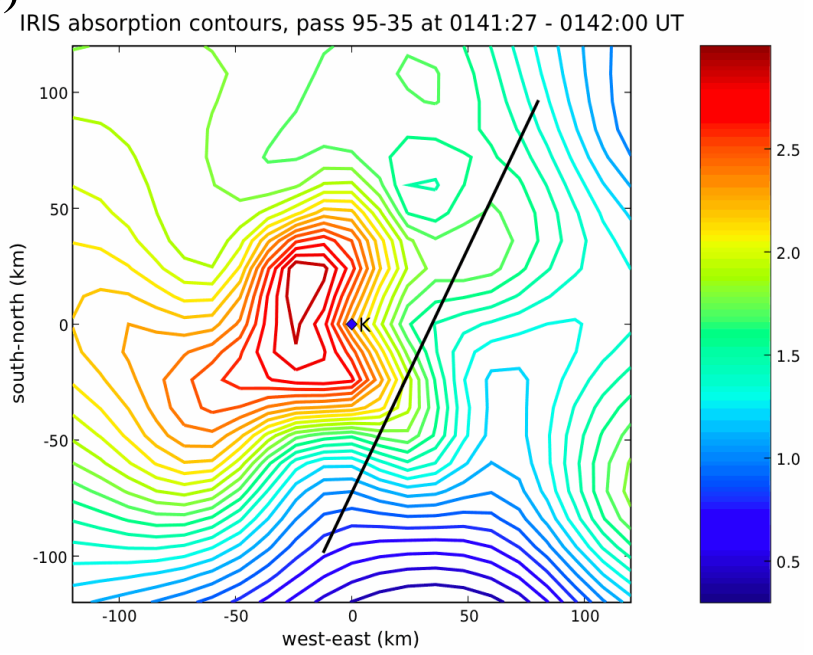

Fig. 3. The distribution of absorption (in decibels) at $90 \mathrm{~km}$ altitude for the time of the overpasses by (a) NOAA-12 from 07:16:35 to 07:17:08 UT on day 125 (5 May), and (b) NOAA-14 from 01:41:27 to 01:42:00 on day 35 (4 February), both in 1995, observed using the Kilpisjärvi imaging riometer. Also shown, in black, is the projected track of the satellite.

By taking the maximum change of flux over any 2-s interval during the pass we are effectively selecting just the greatest variations within a time of about $40 \mathrm{~s}$ in each case. It is clear, nevertheless, that there are significant differences in the fine-scale structure between the trapped and the precipitated components of the electron flux, and that the magnitude of this effect depends on the time of day. The precipitated flux invariably changes more than the trapped component, and the variations are largest in the morning sector $(\sim 08: 30 \mathrm{LT})$ and least at noon $(\sim 12: 30 \mathrm{LT})$. However, these properties are very similar for the $>30 \mathrm{keV}$ and $>100 \mathrm{keV}$ fluxes, indicating that no significant change of spectrum occurs during these rapid variations.

\section{Relations between radio absorption and particle flux.}

\subsection{Data from the whole day}

The imaging riometer at Kilpisjärvi measures the absorption of the cosmic radio noise at $38.2 \mathrm{MHz}$ within a region of about $240 \mathrm{~km}$ north-south and east-west, assuming that the absorption occurs in the ionospheric D-region at altitude
$90 \mathrm{~km}$. The system forms 49 beams from which a spatial distribution may be obtained by interpolation. Figure 3 (a and b) shows the distributions of absorption (in decibels) obtained for the times of the overpasses by (a) NOAA-12 from 07:16:35 UT to 07:17:08 UT on day 125 (5 May), and (b) NOAA-14 from 01:41:27 to 01:42:00 on day 35 (4 February), both in 1995 . The satellite tracks projected to $90 \mathrm{~km}$ altitude are marked in black. An absorption value was then obtained for each 2-s interval along the track, and these are shown (plotted as absorption squared) in Fig. 4 with the precipitated and trapped fluxes observed on the satellite. Figure 5 shows the evolution of the absorption patterns at 30-s resolution for 5-min periods centred on the time of the overpasses.

Two significant facts are immediately evident. Since the overall absorption pattern changes relatively little during a period of several minutes, the variations of particle flux observed during an overpass (which lasts only about $40 \mathrm{~s}$ ) must be spatial rather than temporal. The continuity equation appropriate to the D-region, $q=\alpha_{\mathrm{e}} N_{\mathrm{e}}^{2}$ (where $q$ is the ion production rate, $\alpha_{\mathrm{e}}$ is the effective recombination coefficient, and $N_{\mathrm{e}}$ is the equilibrium electron density), indicates that the 

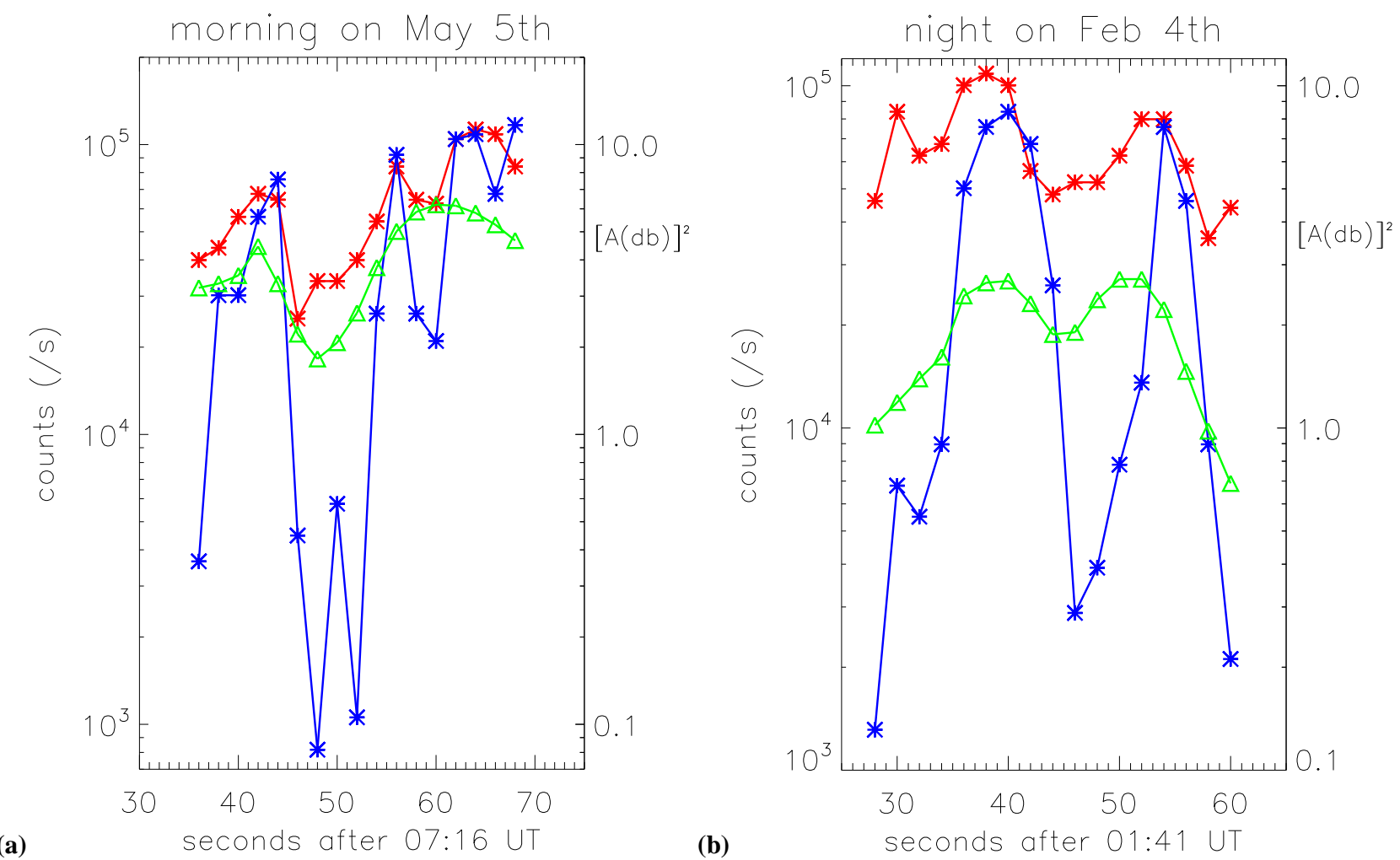

Fig. 4. Comparison of $[A(\mathrm{db})]^{2}$ (green) with precipitated (blue) and trapped (red) count rates at $30 \mathrm{keV}$, for the times of the overpasses by (a) NOAA-12 from 07:16:35 to 07:17:08 UT on day 125 (5 May), and (b) NOAA-14 from 01:41:27 to 01:42:00 on day 35 (4 February), both in 1995, in the morning and night sectors, respectively.

square of the absorption (in decibels) should be proportional to the flux of incoming ionising particles. It appears from Fig. 4 that the square of the absorption is more nearly proportional to the trapped flux than to the precipitated. This apparent anomaly will be considered later.

Twelve overpasses were selected as a subset of those used in the previous section, four in the night sector, five in the morning, and three near noon, the criteria being (i) that the satellite's position, projected to $90 \mathrm{~km}$ altitude, crossed the latitude of Kilpisjärvi within $2^{\circ}$ of longitude of the station, and (ii) that the $38.2 \mathrm{MHz}$ absorption on the wide-beam riometer at the site was at least $1 \mathrm{~dB}$. The ratio between the $>80 \mathrm{keV}$ proton telescope count rate and the coincident $>30 \mathrm{keV}$ electron telescope count rate indicates whether or not the electron measurements are contaminated by significant response to energetic protons and should be discarded. Using this additional criterion two passes were rejected, one in the noon sector and one at night, leaving the selection shown in Table 2. Included is the $K_{p}$ index for the 10 passes, which shows that the corresponding geomagnetic activity was moderate, ranging from $3+$ to $5+$.

Scatter plots of absorption against electron count rate from the precipitated and trapped detectors are given in Fig. 6 (a and b), all 10 passes being included. Regression lines are su- perimposed for absorption against count rate, and for count rate against absorption, as are the trends corresponding to the theoretical square law. Detailed results from the regression analysis are given in Table 3 . Using these equations the absorption could be estimated from the particle flux to an accuracy of a factor of about 1.4, and the flux from the absorption to better than a factor of 2 or 3 . These factors are the standard errors, which would contain about $70 \%$ of estimates.

Table 4 gives relationships between electron pitch angles at the equator $(L=5.9)$, at altitude $850 \mathrm{~km}$, and at $90 \mathrm{~km}$ (a typical height for the absorption layer), according to the first invariant (magnetic flux) for trapped particles. The flux reaching $90 \mathrm{~km}$ has pitch angles between $0^{\circ}$ and $3.24^{\circ}$ at the equator, a range which goes beyond the outer limit for the precipitated detector $\left(2.03^{\circ}\right)$ but does not quite reach the coverage of the trapped detector $\left(3.42^{\circ}\right.$ to $\left.3.84^{\circ}\right)$. This suggests that a better measure of the flux reaching $90 \mathrm{~km}$ might be achieved by taking account of the readings from both detectors, and Fig. 6c shows the plot of absorption against the geometric mean of the precipitated and trapped count rates. Regression analysis details are included in Table 3. The central line of this distribution, the geometric mean of the two regression lines, has a gradient of 0.46 . 

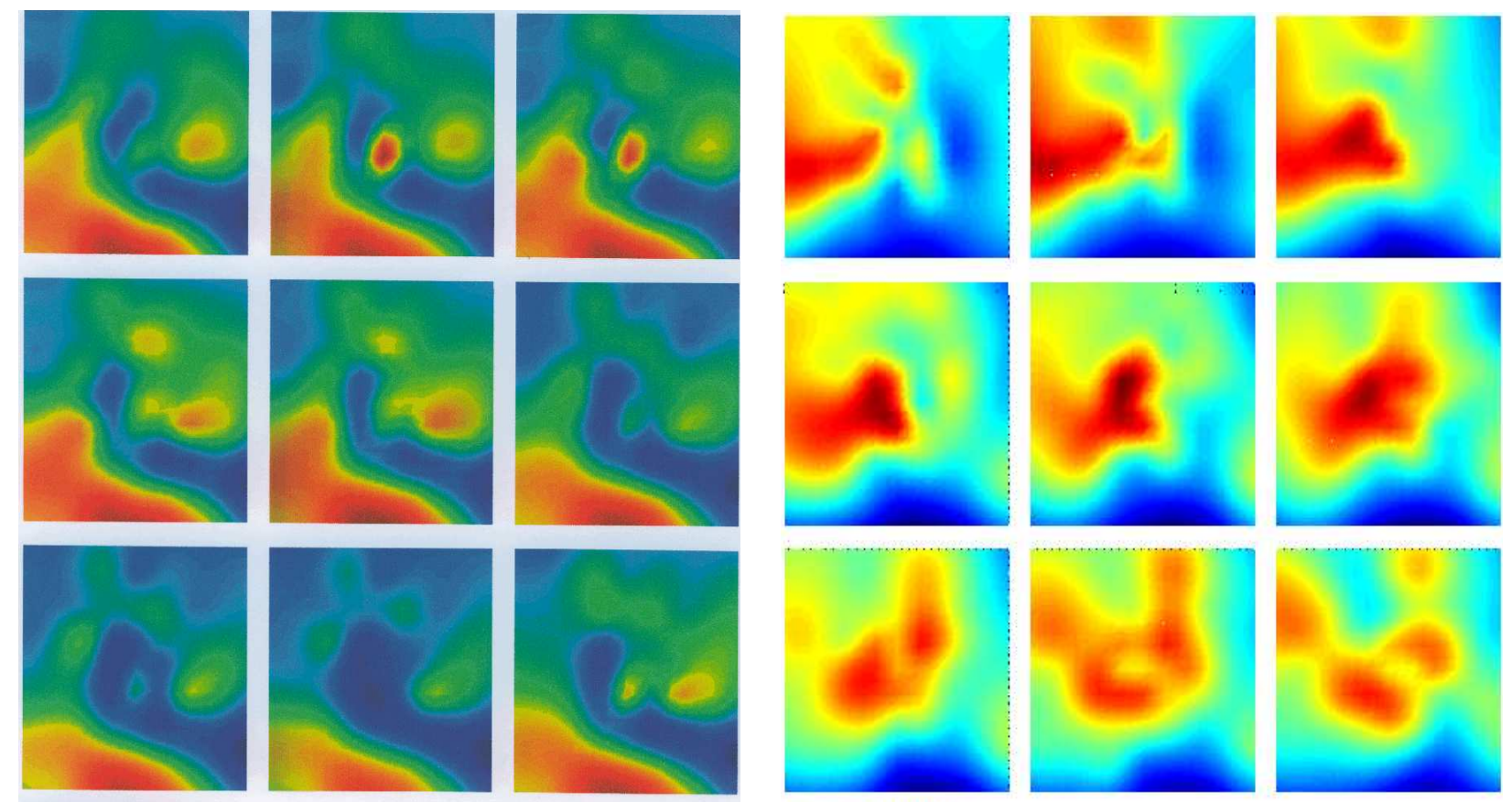

(a) $\stackrel{1}{\operatorname{Absorption}} \stackrel{2}{2} \mathrm{~dB} @ 38.2 \mathrm{3}$

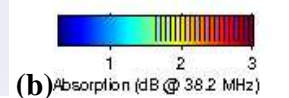

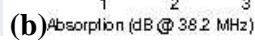

Fig. 5. Absorption distributions over a $240 \mathrm{~km}$ square, centred on Kilpisjärvi, at 30-s resolution, for the times of two overpasses: (a) 5 May 1995 from 07:14:30 to 07:19:00 UT; and (b) 4 February 1995 from 01:39:30 to 01:44:00 UT. Each panel covers the same area as Fig. 3.

Table 2. Overpasses of Kilpisjärvi during significant radio absorption (passes on 13 March and 9 October 1995 having been removed because of possible proton contamination).

\begin{tabular}{llrcccc}
\hline Satellite & Pass & Date & UT & Max W/B abs(dB) & Max IRIS abs(dB) & Kp \\
\hline NOAA-14 & $95-035$ & 1995 Feb 04 & 0142 & 2.8 & 1.65 & $5+$ \\
& $95-128$ & May 08 & 0145 & 2.5 & 1.87 & $4+$ \\
& $95-276$ & Oct 03 & 0156 & 1.1 & 0.86 & $4+$ \\
NOAA-12 & $94-282$ & 1994 Oct 09 & 0726 & 1.8 & 1.02 & $5-$ \\
& $95-125$ & 1995 May 05 & 0717 & 2.9 & 2.49 & $5-$ \\
& $95-222$ & Aug 10 & 0709 & 1.4 & 1.39 & $3+$ \\
& $95-282$ & Oct 09 & 0704 & 2.3 & 1.71 & $5-$ \\
& $95-305$ & Nov 01 & 0704 & 2.7 & 2.36 & $4+$ \\
NOAA-14 & $95-058$ & 1995 Feb 27 & 1055 & 1.9 & 1.57 & 4 \\
& $95-086$ & Mar 27 & 1055 & 1.0 & 0.69 & $3+$ \\
\hline
\end{tabular}

\subsection{Separate results from three times of day.}

Results of regression analysis for each of the three local time groups are summarised in Table 5 in terms of flux $F_{\mathrm{M}}\left(=100 \times C_{\mathrm{M}}\right)$, where $F_{\mathrm{M}}$ is the geometric mean of the fluxes measured by the precipitated and trapped detectors. If $F_{\mathrm{M}}=10^{6} \mathrm{~cm}^{-2} \mathrm{~s}^{-1} \mathrm{sr}^{-1}$ we would predict the $38.2 \mathrm{MHz}$ absorption to be $0.84,1.04$ and $1.07 \mathrm{~dB}$ for night, morning and noon, respectively, to an accuracy of 20 to $30 \%$. The absorp- tion predicted for the morning sector exceeds that predicted for the night period at a given level of $30 \mathrm{keV}$ flux, and this holds across the whole range of interest $\left(F_{\mathrm{M}}=10^{5}\right.$ to $\left.10^{7}\right)$. However, the noon values can be smaller or larger than the morning values depending on the intensity. We attribute this to a systematic variation of spectrum (Sect. 6.1). 
Table 3. Summary of the statistics from Fig. 6, showing the regression analysis for the whole day between $\log (\operatorname{absorption})$ and $\log (30 \mathrm{keV}$ count rate) both for the trapped and precipitated populations, and for their geometric mean. In the table, $A=\operatorname{absorption}(\mathrm{dB}), y=\log [A]$ and $x=\log ($ count rate) or $\log ($ flux $)$.

\begin{tabular}{|c|c|c|}
\hline Parameter & In terms of count rate $(C)$ & In terms of flux $(F)$ \\
\hline \multicolumn{3}{|l|}{ Precipitated } \\
\hline Correlation coefficient, & \multicolumn{2}{|c|}{0.69} \\
\hline Regression of $y$ on $x$ & $y=0.224 x-0.843$ & $y=0.224 x-1.292$ \\
\hline$A=f^{n}\left(C_{\mathrm{P}}\right.$ or $\left.F_{\mathrm{P}}\right)$ & $A=1.437 \times 10^{-1} C_{\mathrm{P}}^{0.224}$ & $A=5.107 \times 10^{-2} F_{\mathrm{P}}^{0.224}$ \\
\hline Standard error (as factor) & \multicolumn{2}{|c|}{$\begin{array}{lll}\mathrm{P} & 1.37 & \mathrm{P} \\
\end{array}$} \\
\hline Regression of $x$ on $y$ & $x=2.125 y+3.927$ & $x=2.125 y+5.927$ \\
\hline$\left(C_{\mathrm{P}}\right.$ or $\left.F_{\mathrm{P}}\right)=f^{n}(A)$ & $C_{\mathrm{P}}=8.453 \times 10^{3} A^{2.125}$ & $F_{\mathrm{P}}=8.453 \times 10^{5} A^{2.125}$ \\
\hline Standard error (as factor) & \multicolumn{2}{|c|}{2.65} \\
\hline \multicolumn{3}{|l|}{ Trapped } \\
\hline Correlation coefficient, & \multicolumn{2}{|c|}{0.69} \\
\hline Regression of $y$ on $x$ & $y=0.366 x-1.579$ & $y=0.366 x-2.311$ \\
\hline$A=f^{n}\left(C_{\mathrm{T}}\right.$ or $\left.F_{\mathrm{T}}\right)$ & $A=2.636 \times 10^{-2} C_{\mathrm{T}}^{0.366}$ & $A=4.891 \times 10^{-3} F_{\mathrm{T}}^{0.366}$ \\
\hline Standard error (as factor) & \multicolumn{2}{|c|}{$\begin{array}{lllllll}1 & 1.37 & 1\end{array}$} \\
\hline Regression of $x$ on $y$ & $x=1.290 y+4.419$ & $x=1.290 y+6.419$ \\
\hline$\left(C_{\mathrm{T}}\right.$ or $\left.F_{\mathrm{T}}\right)=f^{n}(A)$ & $C_{\mathrm{T}}=2.624 \times 10^{4} A^{1.290}$ & $F_{\mathrm{T}}=2.624 \times 10^{6} A^{1.290}$ \\
\hline Standard error (as factor) & \multicolumn{2}{|c|}{1.82} \\
\hline \multicolumn{3}{|l|}{ Geometric mean $\sqrt{P T}$} \\
\hline Correlation coefficient, & \multicolumn{2}{|c|}{0.75} \\
\hline Regression of $y$ on $x$ & $y=0.328 x-1.339$ & $y=0.328 x-1.995$ \\
\hline$A=f^{n}\left(C_{\mathrm{M}}\right.$ or $\left.F_{\mathrm{M}}\right)$ & $A=4.581 \times 10^{-2} C_{\mathrm{M}}^{0.328}$ & $A=1.011 \times 10^{-2} F_{\mathrm{M}}^{0.328}$ \\
\hline Standard error (as factor) & \multicolumn{2}{|c|}{$\begin{array}{lll}\mathrm{M} & 1.34 & \mathrm{M}\end{array}$} \\
\hline Regression of $x$ on $y$ & $x=1.708 y+4.173$ & $x=1.708 y+6.173$ \\
\hline$\left(C_{\mathrm{M}}\right.$ or $\left.F_{\mathrm{M}}\right)=f^{n}(A)$ & $C_{\mathrm{M}}=1.489 \times 10^{4} A^{1.708}$ & $F_{\mathrm{M}}=1.489 \times 10^{6} A^{1.708}$ \\
\hline Standard error (as factor) & \multicolumn{2}{|c|}{1.93} \\
\hline Central line & $\begin{array}{c}y=0.457 x-1.891 \\
A=1.285 \times 10^{-2} C_{\mathrm{M}}^{0.457}\end{array}$ & $\begin{array}{c}y=0.457 x-2.805 \\
A=1.568 \times 10^{-3} C_{\mathrm{M}}^{0.457}\end{array}$ \\
\hline
\end{tabular}

Table 4. Pitch angle relationships assuming the first invariant $(\sin (\alpha) \propto \sqrt{B})$ and a dipole field.

\begin{tabular}{cccc}
\hline & $\alpha_{90}$ & $\alpha_{850}$ & $\alpha_{e q}$ \\
\hline$h=90 \mathrm{~km}$ & $0^{\circ}$ & & $0^{\circ}$ \\
& $90^{\circ}$ & & $3.24^{\circ}$ \\
\hline Vertical & & $2^{\circ}$ & $0.13^{\circ}$ \\
detector & $17^{\circ}$ & $1.12^{\circ}$ \\
& $32^{\circ}$ & $2.03^{\circ}$ \\
\hline Horizontal & $63^{\circ}$ & $3.42^{\circ}$ \\
detector & & $78^{\circ}$ & $3.76^{\circ}$ \\
& & $90^{\circ}$ & $3.84^{\circ}$ \\
\hline
\end{tabular}

\section{Relations between trapped and precipitated flux}

\subsection{Diffusion parameters}

The preferred explanation of electron precipitation from a population of trapped electrons in the tens of $\mathrm{keV}$ energy range uses the theory of pitch-angle scattering involving whistler-mode (VLF) electromagnetic waves (Kennel and Petscheck, 1966; Kennel, 1969; Thorne, 1972). The rate of deposition into the atmosphere depends on the rate at which trapped electrons diffuse into the loss cone (from which, by definition, they are lost to the atmosphere at the next bounce), and this is governed by a "diffusion parameter" $\sqrt{D \tau}$, where $D$ is a diffusion coefficient and $\tau$ is related to the bounce time of a particle between hemispheres. The mechanism relies on a resonance between the gyrating electrons and the Doppler-shifted whistler-mode waves which they emit. The waves may have been generated in the same flux tube as those being affected, or have come in from elsewhere. Thorne (1972) calls these cases "unstable" and "parasitic", 
Table 5. Regression analysis for the three periods of the day, in terms of $F_{\mathrm{M}}$.

\begin{tabular}{ccccccc}
\hline Period & $\rho$ & $A\left(F_{\mathrm{M}}\right)$ & S.E. & $F_{\mathrm{M}}(A)$ & S.E. & Central line \\
\hline Night & 0.70 & $A=1.507 \times 10^{-2} F_{\mathrm{M}}^{0.291}$ & 1.30 & $F_{\mathrm{M}}=2.291 \times 10^{6} A^{1.685}$ & 1.87 & $A=1.589 \times 10^{-3} F_{\mathrm{M}}^{0.442}$ \\
Morning & 0.69 & $A=1.264 \times 10^{-2} F_{\mathrm{M}}^{0.319}$ & 1.32 & $F_{\mathrm{M}}=1.489 \times 10^{6} A^{1.501}$ & 1.82 & $A=9.876 \times 10^{-4} F_{\mathrm{M}}^{0.493}$ \\
Noon & 0.91 & $A=5.897 \times 10^{-4} F_{\mathrm{M}}^{0.543}$ & 1.21 & $F_{\mathrm{M}}=8.356 \times 10^{5} A^{1.520}$ & 1.38 & $A=2.742 \times 10^{-4} F_{\mathrm{M}}^{0.600}$ \\
\hline
\end{tabular}

Table 6. Precipitated-to-trapped flux ratios, and corresponding diffusion parameters, for $30 \mathrm{keV}$ electrons.

\begin{tabular}{llll}
\hline Period & Quantity & Median & Quartiles \\
\hline Night & $C_{\mathrm{p}} / C_{\mathrm{T}}$ & 0.238 & $0.088,0.581$ \\
& $\sqrt{D \tau}$ & 0.020 & $0.014,0.043$ \\
\multirow{2}{*}{ Morning (all) } & $C_{\mathrm{P}} / C_{\mathrm{T}}$ & 0.643 & $0.356,0.887$ \\
& $\sqrt{D \tau}$ & 0.048 & $0.027,0.130$ \\
Noon & $C_{\mathrm{P}} / C_{\mathrm{T}}$ & 0.500 & $0.326,0.556$ \\
& $\sqrt{D \tau}$ & 0.036 & $0.026,0.041$ \\
\multirow{2}{*}{ Morning subgroup } & $C_{\mathrm{P}} / C_{\mathrm{T}}$ & 0.090 & \\
& $\sqrt{D \tau}$ & 0.014 & \\
\hline
\end{tabular}

respectively. Figure 7 shows the dependence of the flux on equatorial pitch-angle and diffusion parameter under this mechanism. By observing the ratio between the trapped and precipitated fluxes, in our case corresponding to equatorial pitch-angles $1.12^{\circ}$ and $3.76^{\circ}$ (see Table 4 ), it should be possible to estimate values for the diffusion parameter, as shown in Fig. 8.

Values for the ratio of precipitated to trapped count rates are plotted against $A^{2}$ in Fig. 9 for the 10 Kilpisjärvi overpasses at 2-s intervals, divided according to the night, morning and noon sectors. The median and quartile values for each interval, with corresponding diffusion parameters derived from Fig. 8, are given in Table 6. The distribution of ratios for the morning period (Fig. 9b) has groups of points of low value seemingly separated from the main distributions. These would appear to correspond to the large, short-duration reductions of precipitated flux noted previously. Median values of the count rate ratio and corresponding diffusion parameters are included in Table 6. The interquartile range is no more than a factor of 2 for the morning and noon data, though considerably more at night. The corresponding range of the diffusion parameter is a factor of 3 or less. The relative effect of a change of diffusion parameter increases sharply at the lower values.

In the morning sector it is noteworthy that there is a tendency for the low ratios to occur at the smaller values of $A^{2}$ within an individual pass, not necessarily at the lowest values for the sector overall. For example, the low ratios occur when $A^{2}$ is from 0.5 to 0.7 in passes $95-222$ and 94-282, but between 2 and 3 in passes 95-282 and 95-125. This suggests that the behaviour is also being influenced by some factor other than the flux level, and one which changes from time to time.

\subsection{The noon sector}

Figure 10 shows the relationship between the count rates for the trapped $\left(C_{\mathrm{T}}\right)$ and precipitated $\left(C_{\mathrm{P}}\right)$ components during the two overpasses (95-058 and 95-086) recorded in the noon sector; both the $100 \mathrm{keV}$ and the $30 \mathrm{keV}$ data are plotted. The data cover 4 orders of magnitude in $C_{\mathrm{P}}$. The correlation coefficient (between the logarithms) is $\rho=0.963$, and the regression equation for $C_{\mathrm{P}}$ against $C_{\mathrm{T}}$ is

$C_{\mathrm{P}}=4.02 \times 10^{-5} C_{\mathrm{T}}^{1.999}$

with standard error a factor of 1.94. The probability of this value of $\rho$ occurring by chance in a data set of 72 points is about $10^{-57}$ !

Two points are noteworthy here. First, the same relationship applies to both energy ranges, so presumably it is not energy dependent. Second, the two passes whose data fit so well to the same law were recorded a month apart (February and March of 1995). This does not guarantee that the same relationship would hold for all such observations, but it does suggest a certain stability in the mechanism.

A similar relationship was found in a previous investigation (Birch et al., 2009) which used hourly values derived from all overpasses in the LT sector 11.5-12.5 over invariant latitudes $65-70^{\circ}$ during a period of $6 \mathrm{~h}$ on one day having enhanced solar wind. In this case the raw data were averages over $16 \mathrm{~s}$ (implying spatial averaging over $120 \mathrm{~km}$ ). The relationship was of the form of Eq. (4) but the constant of proportionality was $4.06 \times 10^{-6}$ instead of $4.02 \times 10^{-5}$. These observations were in the month of July. The suggestion, therefore, is that in the noon sector the precipitated/trapped ratio is essentially proportional to the trapped flux, but the proportionality may change, possibly with the time of year. No such relationship was found in the data from the night or morning sectors. 

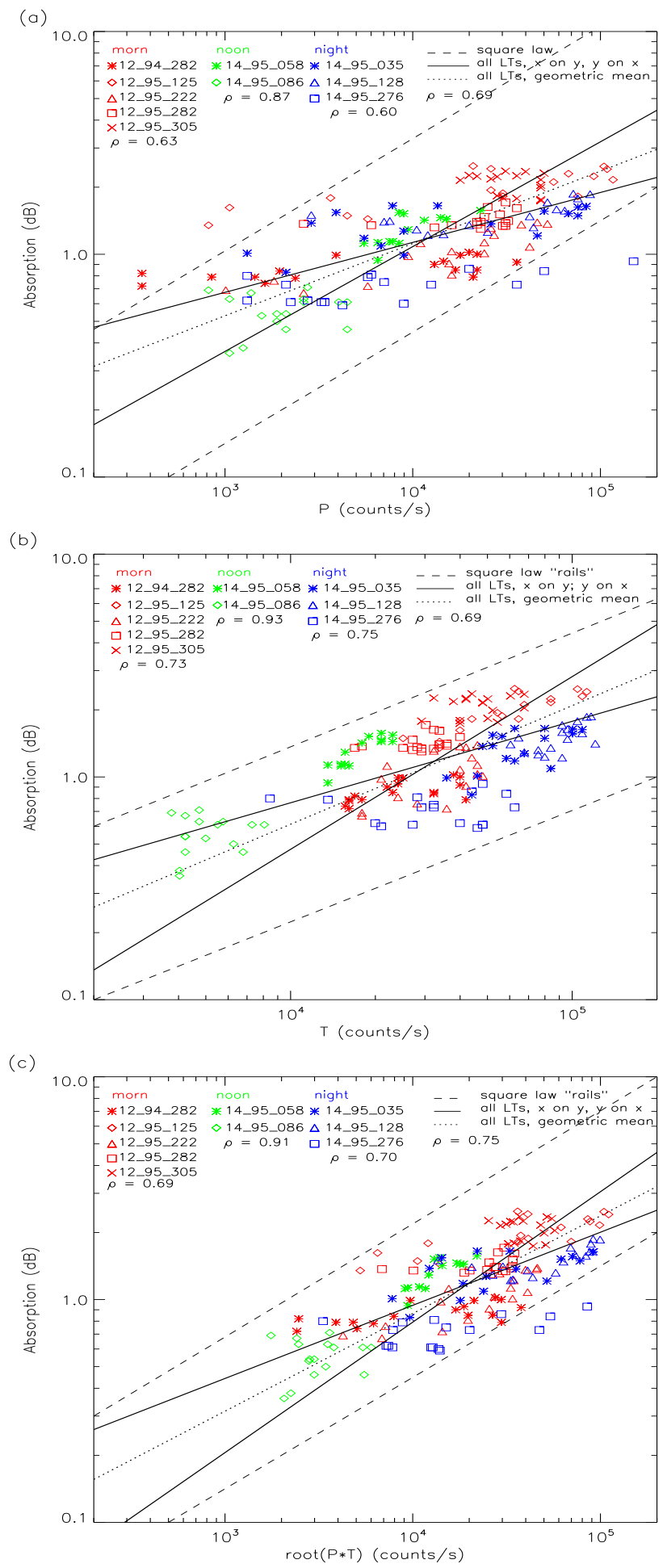

Fig. 6. Variation of $38.2 \mathrm{MHz}$ absorption with (a) precipitated count rate $P_{30}(/ \mathrm{s}),(\mathbf{b})$ trapped count rate $T_{30}(/ \mathrm{s})$, and (c) $\sqrt{P_{30} T_{30}}$, for 10 selected passes in the morning, noon and night sectors, showing individual passes colour-grouped in local time, regression lines for the population as a whole (x-on-y and $y-o n-x$ as solid lines, geometric mean as a dotted line), square law "rails" (dashed lines) for comparison, and correlation coefficients for each local time group, and the population as a whole.

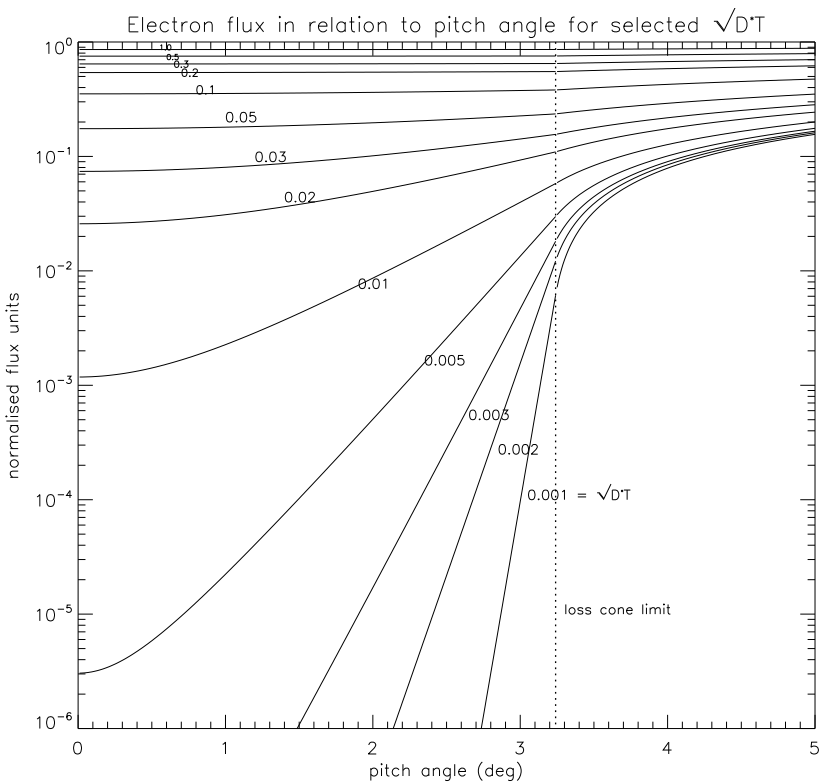

Fig. 7. Electron flux in relation to pitch angle for selected values of diffusion parameter (after Kennel and Petschek, 1966).

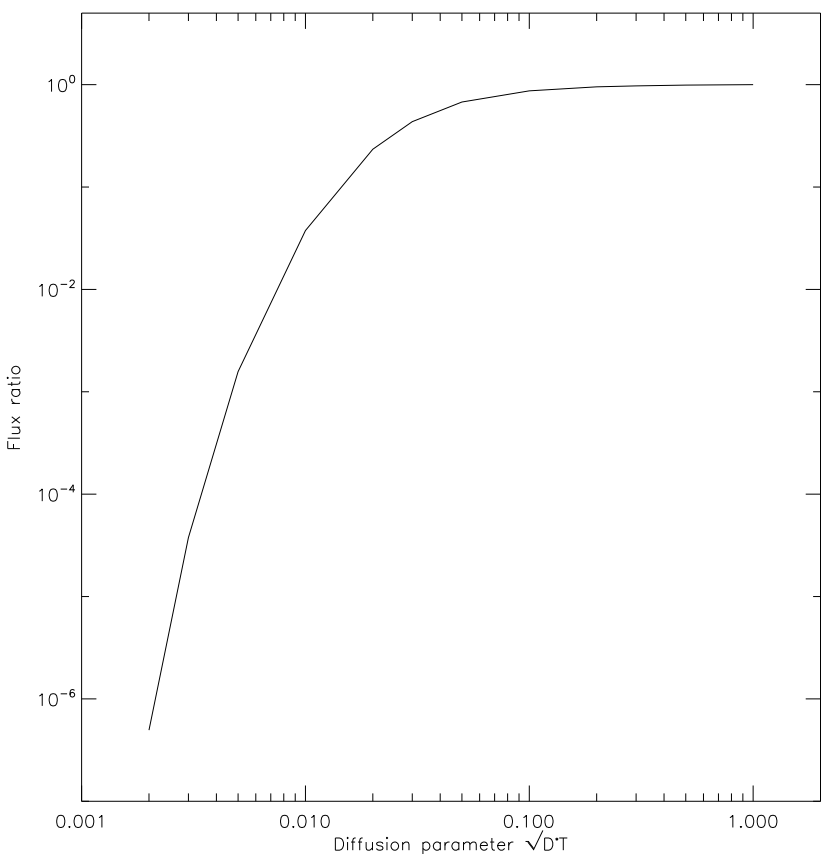

Fig. 8. Ratio between precipitated and trapped electron fluxes (each integrated across their respective detectors) as a function of diffusion parameter.

\section{Spectral variations}

\subsection{The flux reaching $90 \mathrm{~km}$}

The spectral information provided by POES is limited to counting rates above the $30 \mathrm{keV}, 100 \mathrm{keV}$ and $300 \mathrm{keV}$ thresholds. The form of the spectrum is not known but ratios 

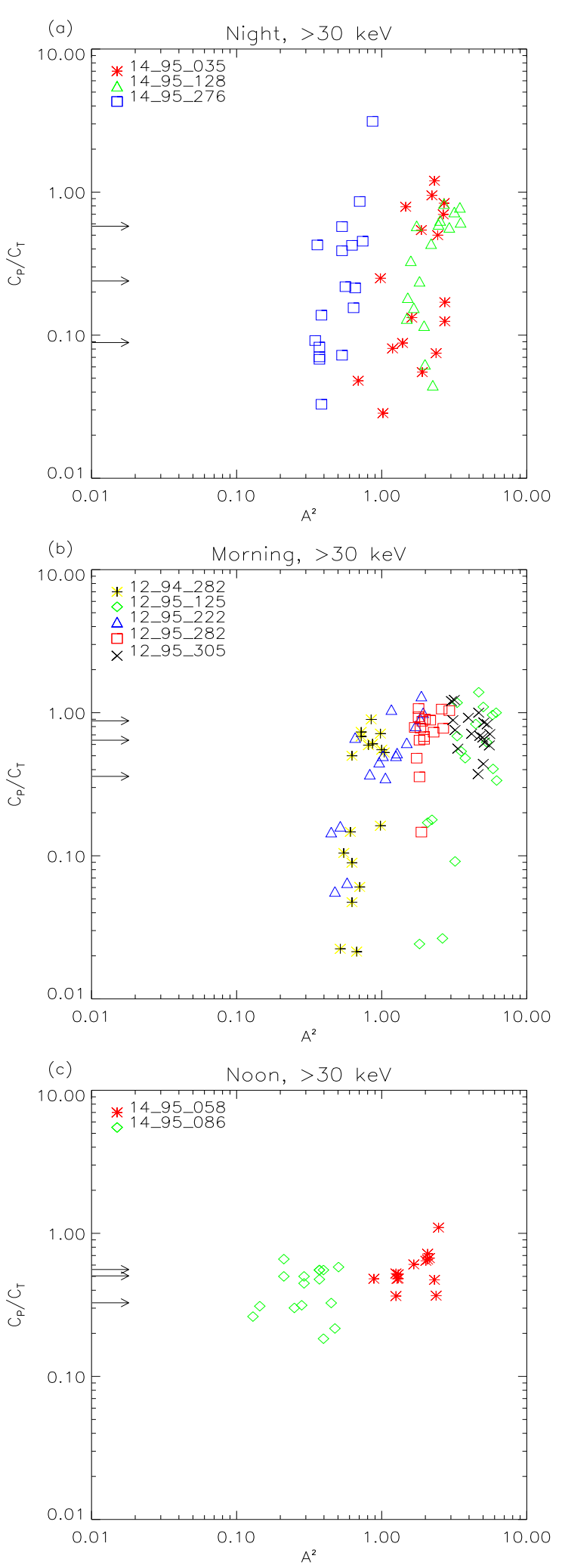

Fig. 9. Ratio of precipitated to trapped $30 \mathrm{keV}$ count rates against $A^{2}$ at 2-s intervals for the 10 Kilpisjärvi overpasses, divided into night, morning, and noon sectors. (The arrows mark the medians and quartiles.)

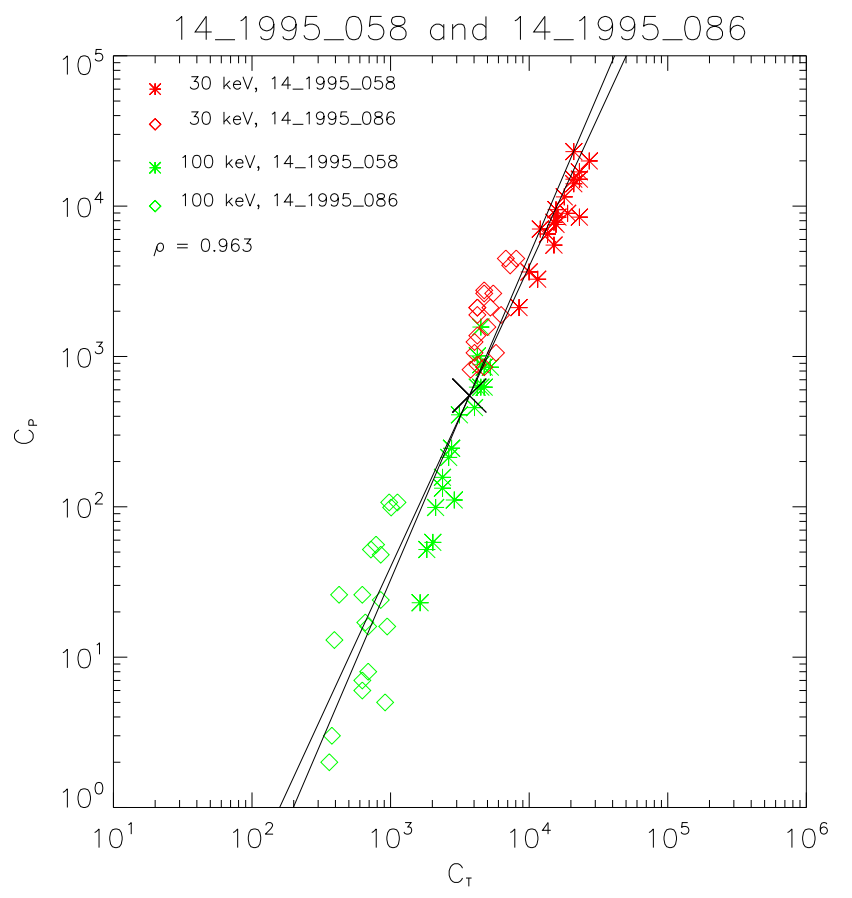

Fig. 10. Precipitated against trapped count rates for "noon" overpasses on days 27 February and 27 March 1995, for both $30 \mathrm{keV}$ and $100 \mathrm{keV}$ populations, including regression lines.

between these quantities will provide an indication of the hardness of the spectrum in rather general terms. We have used only the ratio $F(100) / F(30)$, since the count rates above $300 \mathrm{keV}$ may be very small and therefore subject to any lowlevel background (e.g. cosmic rays) that may be present.

Figure 11 plots the 2-s data as $S_{\mathrm{M}}\left(=F_{\mathrm{M}}(100) / F_{\mathrm{M}}(30)\right)$ against (absorption) ${ }^{2}$ for each of the 10 Kilpisjärvi overpasses. Distinct symbols are used for the individual passes, and they are collated into the night (a), morning (b) and noon (c) sectors. $F_{\mathrm{M}}\left(=\sqrt{F_{\mathrm{T}} \times F_{\mathrm{P}}}\right)$ is taken to indicate the flux reaching the $90 \mathrm{~km}$ level; we have seen that $A^{2}$ is well correlated with the magnitude of $F_{\mathrm{M}}$, being essentially proportional to it. Thus, a ten-fold increase in $A^{2}$ may be taken to indicate a ten-fold increase in $30 \mathrm{keV}$ flux reaching $90 \mathrm{~km}$.

A pseudo-characteristic energy, $E_{0}$, related to the spectral ratio by $E_{0}=\left(E_{1}-E_{2}\right) / \ln (S)$, is also indicated, where $E_{1}$ and $E_{2}$ are the thresholds $30 \mathrm{keV}$ and $100 \mathrm{keV}$, and $S$ is the ratio between the $>100$ and $>30 \mathrm{keV}$ fluxes. $E_{0}$ is the characteristic energy in an exponential spectrum.

$f=f_{0} e^{\frac{-E}{E_{0}}}$.

The following points are noted:

1. The spectral hardness depends on the local time, the night values of $E_{0}$ being smaller on average than those observed in the morning and noon sectors, but more variable. The values of $S_{\mathrm{m}}$ (and $E_{0}$ ) are consistent with those observed in previous studies (Birch et al., 2009). 

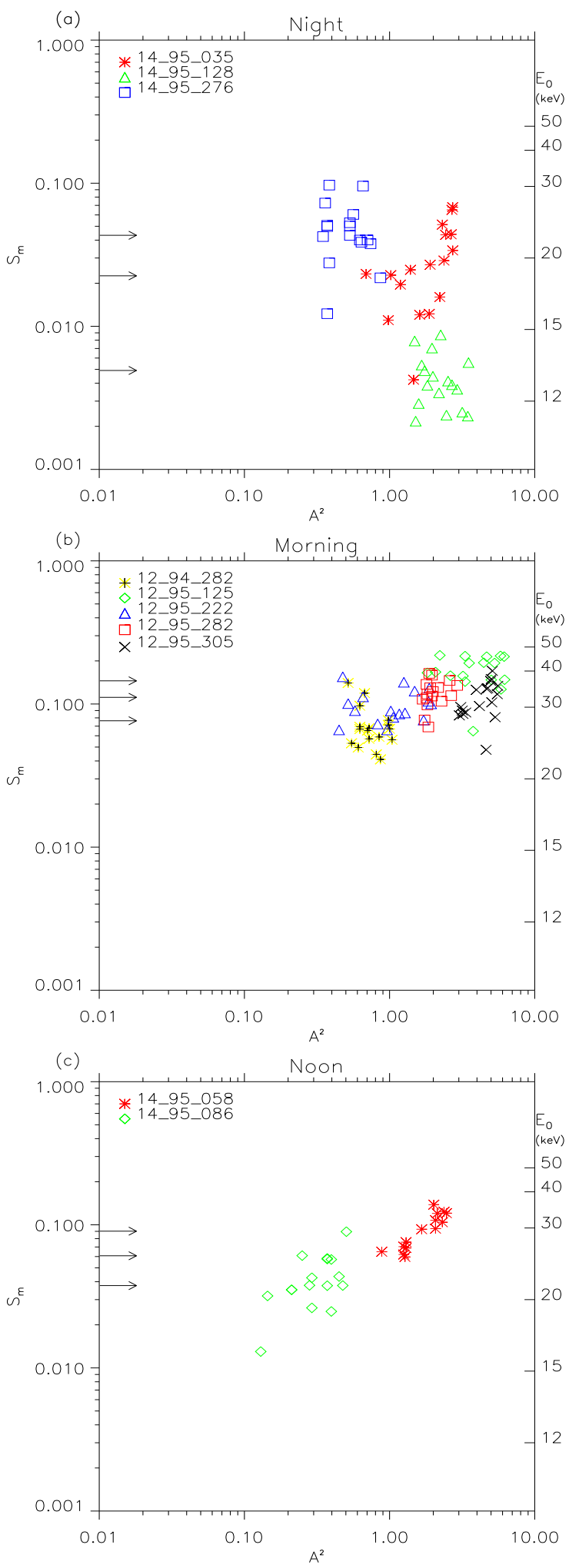

Fig. 11. Geometric mean of the spectral indices $\left(S_{\mathrm{M}}=\sqrt{S_{\mathrm{T}} \times S_{\mathrm{P}}}=\right.$ $\left.F_{\mathrm{M}}(100) / F_{\mathrm{M}}(30)\right)$ against $A^{2}$ at 2-s intervals for the 10 Kilpisjärvi overpasses, divided into night, morning, and noon sectors. (The arrows mark the medians and quartiles.)
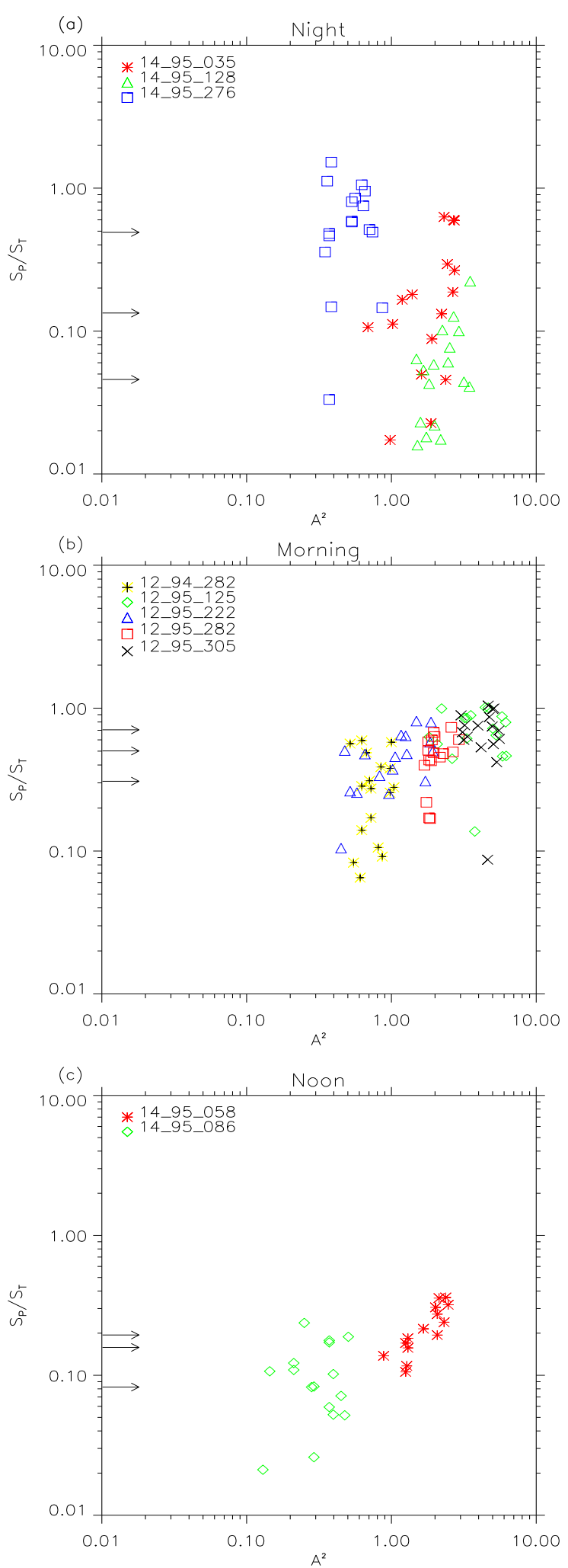

Fig. 12. Spectral hardness ratio against $A^{2}$ at 2-s intervals for the 10 Kilpisjärvi overpasses, divided into night, morning, and noon sectors. (The arrows mark the medians and quartiles.) 
2. There are also differences in spectral hardness between individual passes in the same local time sector, most notably in the night sector where there are variations both within and between individual passes. There is no significant correlation of spectral hardness with $A^{2}$ in this sector.

3. In the morning sector there is some variation of spectral hardness with $A^{2}$ overall, though its significance may be doubted in view of the amount of variation within individual passes, these showing no correlation with $A^{2}$.

4. The noon sector, though represented by only two passes, shows what appears to be a significant variation of spectral hardness with $A^{2}$. Figure $11 \mathrm{c}$ is based on the geometric mean of the values for the trapped and the precipitated components in the noon sector, but detailed examination reveals that both components show a tendency for the hardness to increase with the trapped flux $\left(F_{\mathrm{T}}(30)\right)$, the variation being considerably greater for the precipitated component. According to the theory of pitch-angle scattering by wave-particle interaction, one condition is that the parallel energy of the particle must exceed a threshold value $\left(W_{\|}=B^{2} / 2 \mu_{0} N\right.$, where $B$ is the magnetic flux density, and $N$ the density of cold plasma). This effect would alter the spectral hardness, an increase of $W_{\|}$reducing the $30 \mathrm{keV}$ flux but not the $100 \mathrm{keV}$ flux. However, in this situation an increase of flux would be associated with decreased hardness, the opposite of what is observed.

\subsection{Relative spectral hardness of precipitated and trapped components}

A previous study (Birch et al., 2009) reported that during an active period (associated with high-speed solar wind) the precipitated flux in the morning and noon sectors tends to be softer than the trapped. This is at a time when the trapped flux is enhanced and we expect the resulting radio absorption to be significant. (During times of slower solar wind the trapped flux was considerably weaker but the precipitated component was then harder than the trapped.) Since the spectral hardness ratio

$\frac{S_{\mathrm{P}}}{S_{\mathrm{T}}}=\frac{F_{\mathrm{P}}(100)}{F_{\mathrm{P}}(30)} \times \frac{F_{\mathrm{T}}(30)}{F_{\mathrm{T}}(100)}=\frac{R(100)}{R(30)}$,

(where $R=F_{\mathrm{P}} / F_{\mathrm{T}}$ ), that quantity also compares the precipitated-to-trapped ratios at $>100 \mathrm{keV}$ and $>30 \mathrm{keV}$.

Figure 12 plots this ratio against $A^{2}$ for each of the local time sectors. If these data can be taken as representative, they imply striking differences of behaviour between the sectors. Taking the whole group together, the morning sector shows a tendency for $R_{100} / R_{30}$ to increase with $A^{2}$, though such trends are not convincingly visible for individual overpasses. The noon group shows an increase of $R(100) / R(30)$ consistent with the comments of item 4 in the previous section. The
Table 7. Typical location of field line apex for each time-of-day group.

\begin{tabular}{ccccc}
\hline \multirow{2}{*}{ Group } & \multicolumn{2}{c}{ Ground } & \multicolumn{2}{c}{ Apex } \\
& UT & LT & Distance $\left(R_{\mathrm{e}}\right)$ & LT \\
\hline Night & $01: 45$ & $03: 10$ & 10.0 & $03: 00 \mathrm{~h}$ \\
Morning & $07: 10$ & $08: 35$ & 7.5 & $09: 00 \mathrm{~h}$ \\
Noon & $10: 55$ & $12: 20$ & 7.0 & $13: 00 \mathrm{~h}$ \\
\hline
\end{tabular}

data from the night sector, on the other hand, are extremely variable. The points from each pass tend to clump together, but without systematic variation with $A^{2}$, either within or between the clumps.

\section{Conclusions and discussion}

\subsection{Main conclusions}

1. The correlation between the detailed structure of an auroral absorption event and the fluxes of $>30 \mathrm{keV}$ electrons detected by an overflying satellite are close enough for one quantity to be predicted from the other with good accuracy: the flux from the absorption with standard error better than a factor of 2 , or the absorption from the flux with standard error a factor of about 1.3.

2. The best agreement is obtained by taking the geometric mean of the trapped and precipitated flux to represent the energetic electron flux reaching $90 \mathrm{~km}$. The relationship between flux and absorption depends somewhat on the local time, no doubt due to variations of spectrum.

3. The details of the spatial structure do not change significantly throughout the duration of a satellite overpass, implying that the fine structure in the particle flux is essentially spatial rather than temporal.

4. The amount of variation represented by the fine structure also depends on the local time, being least at noon and greatest in the morning sector. In every case the precipitated flux varies more than the trapped component. This is consistent with the concept of trapped electrons being scattered into the loss cone, but with a dependence on conditions in the region of the magnetosphere involved in the scattering process.

5. In the noon sector the precipitated and the trapped fluxes are highly correlated, having a square law relationship $\left(F_{\mathrm{P}} \propto F_{\mathrm{T}}^{2}\right)$. This close relationship was not found in the morning or the night sectors.

\subsection{Discussion}

We have noted significant differences of behaviour between the three local times covered by our data. Presumably 
these must be caused by differences in the characteristics of the regions of the magnetosphere involved in the relevant physical processes. Table 7 gives typical locations for the apexes of field lines originating from Kilpisjärvi at the local times of our "night", "morning" and "noon" groups. These were computed using the GSFC program available from http://modelweb.gsfc.nasa.goc/models/cgm/t96.html, which is based on the T-96 magnetosphere model (Tsyganenko, 1995).

The night group shows an influence of the magnetotail, the field lines being pulled further from the Earth and somewhat tailward. With the Earth's rotation the apex is moving closer to the Earth and the lines are shortening. The circulation of the magnetosphere presumably exaggerates this effect.

The morning group, where the variability is greatest, has no great extension of the field-lines and the acceleration of the trapped electrons appears to be complete at this time, since the noon group is no more energetic. The morning group is within the period of greatest precipitation activity for electrons with energies of "tens of $\mathrm{keV}$ " as indicated by the statistics of auroral absorption and VLF noise (Pope, 1963; Bullough et al., 1969; Hargreaves and Bullough, 1972). Having regard to earlier work, it is suggested that the VLF waves responsible for pitch-angle scattering at this local time were generated at a lower latitude, making this an instance of Thorne's "parasitic" process. The existence of a subgroup with particularly low precipitated/trapped ratio (Fig. 9b) could suggest that these field lines are at times being shielded from the scattering radiation.

The noon group, a mere $4 \mathrm{~h}$ later, has surprisingly different characteristics. Though the energy is unchanged from the morning period, the variability of precipitation is much less and there is a remarkable and clear dependence of the precipitation on the level of trapped flux, strongly suggesting that pitch-angle scattering by Thorne's "unstable" process is in control.

In discussing some of the rocket data on energetic electrons, McDiarmid and Budzinski (1964) remarked that "the phenomena are complicated and extremely variable". That view still holds.

Acknowledgements. We acknowledge the work of W. G. Howarth in the initial stages of this study several years ago, and the participation of B. J. I. Bromage in the programme of work of which this paper forms a part.

Topical Editor R. Nakamura thanks one anonymous referee for her/his help in evaluating this paper.

\section{References}

Baker, D. N., Stauning, P., Hones, E. W., Higbie, P. R., and Belian, R. D.: Near-equatorial, high-resolution measurements of electron precipitation at $\mathrm{L} \approx 6.6, \mathrm{~J}$. Geophys. Res., 86, 2293-2313, 1981.
Birch, M. J., Hargreaves, J. K., and Bromage, B. J. I. B.: Effects of high speed solar wind on energetic electron activity in the auroral regions during July 1-2, 2005, J. Atmos. Solar-Terr. Phys., 71, 1190-1209, 2009.

Browne, S., Hargreaves, J. K., and Honory, B.: An imaging riometer for ionospheric studies, Electronics and Communication Engineering Journal, 7, 209-217, 1995.

Bullough, K., Hughes, A. R. W., and Kaiser, T. R.: Satellite evidence for the generation of VLF emissions at medium latitude by the tranverse resonance instability, Planet. Space Sci., 17, 363374, 1969.

Collis, P. N., Hargreaves, J. K., and Korth, A.: Loss cone fluxes and pitch angle diffusion at the equatorial plane during auroral radio absorption events, J. Atmos. Terr. Phys., 45, 231-243, 1983.

Evans, D. S. and Greer, M. S.: Polar Orbiting Environmental Satellite Space Environment Monitor - 2, Instrument descriptions and archive data documentation (version 1.4), NOAA Technical Memorandum, 2004.

Hargreaves, J. K. and Bullough, K.: Mid-latitude VLF emissions and the mechanism of dayside auroral particle precipitation, Planet. Space Sci., 20, 803-807, 1972.

Jelly, D. H., McDiarmid, I. B., and Burrows, J. R.: Correlation between intensities of auroral absorption and precipitated electrons, Can. J. Phys., 42, 2411-2418, 1964.

Kennel, C. F. and Petschek, H. E.: Limit on stably trapped particle fluxes, J. Geophys. Res., 71, 1-28, 1966.

Kennel, C. F.: Consequences of a magnetospheric plasma, Rev. Geophys. Res., 7, 379-419, 1969.

Maehlum, B. and O'Brien, B. J.: Study of energetic electrons and their relationship to auroral absorption of radio waves, J. Geophys. Res., 68, 997-1010, 1963.

McDiarmid, I. B., Burrows, J. R., Budzinski, E. E., and Wilson, M. D.: Some average properties of the outer radiation zone at 1000 km, Can. J. Phys., 41, 2064-2079, 1963.

McDiarmid, I. B. and Budzinski, E. E.: Angular distributions and energy spectra of electrons associated with auroral events, Can. J. Phys., 42, 2048-2062, 1964.

Parthasarathy, R., Berkey, F. T., and Venkatesan, D.: Auroral electron flux and its relation to broadbeam radiowave absorption, Planet. Space Sci., 14, 65-83, 1966.

Pope, J. H.: A high-latitude investigation of the natural very-lowfrequency electromagnetic radiation known as chorus, J. Geophys. Res., 68, 83-99, 1963.

Reid, G. C. and Collins, C.: Observations of abnormal VHF radio wave absorption at medium and high latitudes, J. Atmospheric Terr. Phys., 14, 63-81, 1959.

Thorne, R. M.: The importance of wave-particle interactions in the magnetosphere. Critical problems of magnetospheric physics, Proc. Joint COSPAR/IAGA/URSI Symposium, Madrid, 211225, Published by National Academy of Sciences, Washington D.C., 1972.

Tsyganenko, N. A.: Modelling the Earth's magnetospheric magnetic field confined within a realistic magnetopause, J. Geophys. Res., 106, 5599-5612, 1995. 